\title{
Effect of Solids on Gas Dispersion Characteristics: Addition of Hydrophobic and Hydrophilic Solids
}

\author{
F. J. Tavera and R. Escudero* \\ Instituto de Investigaciones Metalúrgicas, Universidad Michoacana de San Nicolás de Hidalgo. Santiago Tapia 403, Morelia, \\ Michoacán, México. C.P. 58000 jtavera@umich.mx
}

Received October 7, 2011; Accepted February 29, 2012

\begin{abstract}
There is a controversy on the role of solids in flotation systems in terms of the characteristics of the solid-liquid-gas dispersions. The effect of slurries containing carbon or silica on the characteristics of gas-slurry dispersions generated in a flotation column was studied. Experimental results suggest that hydrophilic solids prevent bubbles coalescence, and produces large bubble surface areas, available to collide and collect particles during flotation. On the other hand slurries with hydrophobic particles produce larger bubbles, affecting both the performance and the hydrodynamics of the process.
\end{abstract}

Key words: hydrophobic solids, hydrophilic solids, gas hold-up, superficial bubble surface flux, bubble coalescence.

\section{Introduction}

Gas hold-up is an important variable that determines the circulation and mixing patterns of gas-liquid or gas-pulp dispersions. Therefore, it determines the flotation efficiency and, furthermore, it affects the residence time of materials in the bubbling system. It has demonstrated that highly hydrophobic particles promote coalescence of neighbouring bubbles by its penetration among them while particles of moderated hydrophobicity have no effect on the coalescence process [1]. It has found that the presence of electrolytes promotes considerable bubble coalescence retardation which is reflected by a substantial reduction of bubble size and more uniform dispersions [2]. Studies have concluded that bubble size is strongly affected by frother concentration only when multi-hole spargers are utilized; however at low frother concentration, the bubble size is much more larger, indicating bubble coalescence as a main mechanism determining the size [3]; also, two range of frother concentration are identified as a function of bubble size, and bubble size depends from the frother hydrocarbon chain [4]. Bubble size strongly depends from the value of surface tension and the utilized bubble generation system, being smaller when a porous plate is utilized as compared with a simple orifice nozzle, and a multiple orifice nozzle [5]. The two-bubble coalescence process was studied in a coalescence cell; it was observed that the coalescence of two bubbles results in the formation of an annular wave forming, due to the very rapid expansion of the hole following the instant of film rupture, the process causes a rippling effect which distorts the newly coalesced bubble and may result of an unstable extension which produces a generation of a small daughter bubble; in coalescence dominated sys-
Resumen. Es controversial el efecto de los sólidos contenidos en una pulpa mineral, en las características de la dispersión en un sistema de flotación. En este trabajo se estudió el efecto del contenido de sólidos (sílica o carbón) en las propiedades de la dispersión generada en una columna de flotación de laboratorio. Resultados experimentales muestran que la presencia de sólidos hidrófilos previenen la coalescencia de burbujas y se crea una mayor área superficial de burbujas, disponible para atrapar sólidos. Por otra parte, las partículas hidrófobos promueven la coalescencia de burbujas y modifican la hidrodinámica del proceso.

Palabras clave: Sólidos hidrófobos, sólidos hidrófílos, fracción de gas retenido, área superficial de burbujas, coalescencia de burbujas.

tems the process results in the generation of significant numbers of bubbles much smaller than the Sauter mean value (100-200 $\mu \mathrm{m}$ vs. $2-3 \mathrm{~mm}$ ) [6]. The bubble size has been measured and predicted as a function of the kinetic energy dissipated by a gas jet; the experimental observations showed that bubble characteristics depend mainly from the value of surface tension, and the superficial gas velocity at the discharge orifice nozzle [7]. It was found that the bubble size in the bubbly flow zone of a flotation column increase with increasing distance from the bottom due to coalescence and kinetic energy distribution, therefore, the characteristics of the gas-liquid dispersion depend from the axial location [8]. The Sauter mean bubble diameter decreases with increasing molecular weight of n-alcohols and their concentration; however, branched chain frothers deviated from this pattern, and they show lower efficiency in reducing bubble size [9]. The use of a two-phase ejector for bubble generation provided a good bubble size control; it was found that air/liquid interface properties and energy dissipation rate play a major role in influencing bubble diameter [10]. In mechanical cells, the mineral flotation rate cannot be related easily to bubble size, gas hold-up or superficial gas velocity individually for different operating conditions; however, when taken together as the bubble surface area flux, can be related to the flotation rate extremely well [11].

As it can be seen, the laboratory and plant data suggest that the overall performance of a flotation process is affected by the characteristics of the gas dispersion (generated by a certain sparger), as well as the physicochemical characteristics of the system; these features together with the geometry of the flotation device determine the efficiency of the process. Nevertheless, it has not been concluded about the effect of 
hydrophobic-hydrophilic solid species on the characteristics of gas-solid-liquid dispersions; therefore, this work is devoted to analyse towards this effect.

\section{Results and discussion}

A good agreement between the estimated gas hold-up from electrical conductivity and that from pressure measurements was observed. Figure 1 shows the validation of both gas holdup estimation techniques.

The gas hold-up in the flotation column was measured for carbon slurries $\left(D_{80}=30 \mu \mathrm{m}\right)$, and silica slurries $\left(D_{80}=30\right.$ $\mu \mathrm{m})$ without additions of frother. The aim of this tests was to observe the behaviour of the gas hold-up as a function of the superficial gas velocity when the slurry is made of hydrophobic solids (i. e., carbon), or hydrophilic solids (silica).

Experimental observations showed that gas hold-up increases with the superficial gas velocity since the amount of gas fed into the column also increases. Such behaviour was observed in both experimental systems: carbon-water slurries and silica-water slurries.

However, the gas hold-up behaviour in the carbon-water slurry is lower than that presented in the silica-slurry flotation system. Furthermore, changes in the gas hold-up with the superficial gas velocity presents a crumple sort of pattern in the carbon-water slurry system, while the change of gas hold-up with changing the superficial gas velocity in the silica-water slurry follows a smooth path .

The behaviour of the carbon-water slurry system suggests the presence of the bubbles coalescence phenomenon, producing larger bubbles, or in some cases slug formation and high turbulences, as it was visually observed.

Figure 2 shows a comparison between gas hold-up values for the two cases tested here, after changing the superficial gas velocity.

In the case of experiments carried out without solids (airwater system), Figure 3 shows the relationship among the gas hold-up and the superficial gas velocity. There is shown that counter-current conditions promote a decrease in the gas hold-
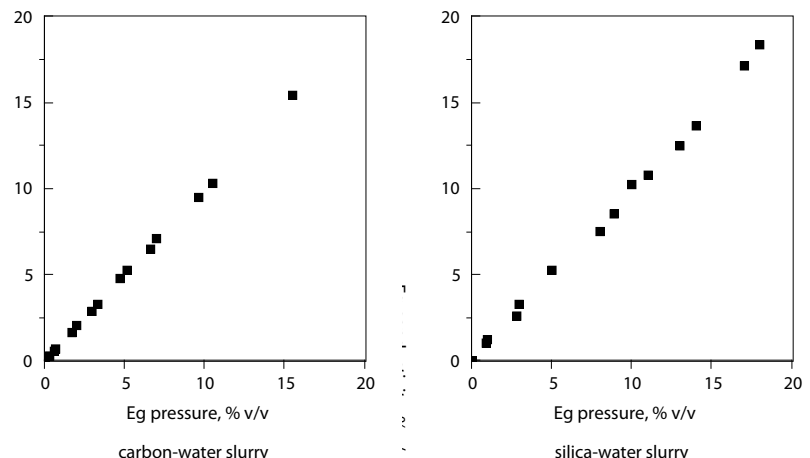

Fig. 1. Gas hold-up (Eg) measurements in gas-solids slurries by using pressure measurements, and through the electrical conductivity method.
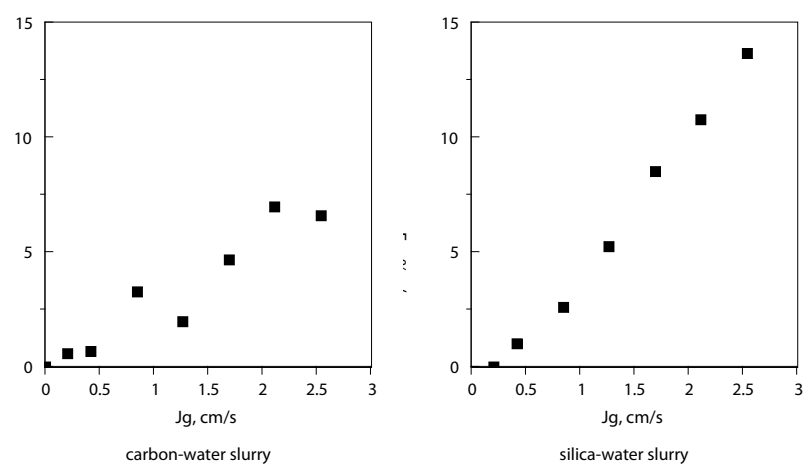

Fig. 2. Gas hold-up (Eg) behaviour as regards the superficial gas velocity $(\mathrm{Jg})$. The flotation systems were operated without frother, and under counter-current conditions.
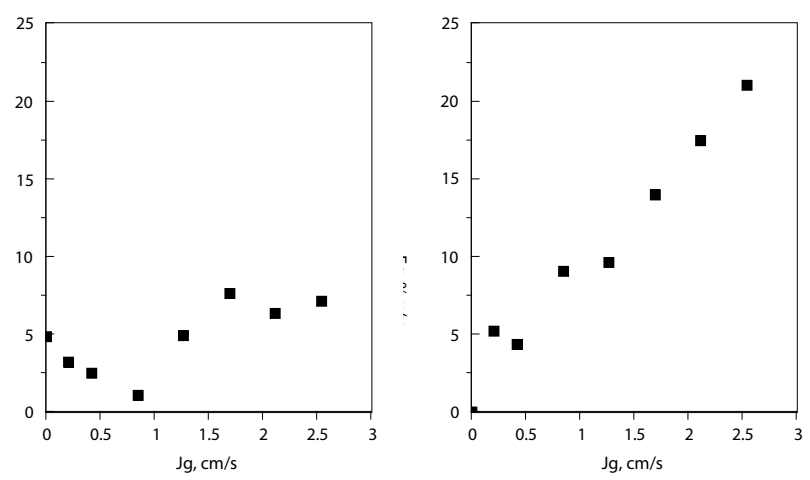

Fig. 3. Gas hold-up (Eg), and superficial gas velocity $(\mathrm{Jg})$ relationships for flotation systems without solids. The column was operated under counter-current (left) and co-current conditions (right).

up perhaps of a larger slip velocity as compared with that observed in the co-current flow conditions, causing bubbles coalescence.

The presence of solids affects the gas hold-up behaviour in a similar manner as when the column is operated without solids (Figure 3), under the two different current schemes: the co-current and counter current phase flow. As presented in Figure 4, it seems that bubble coalescence is promoted under
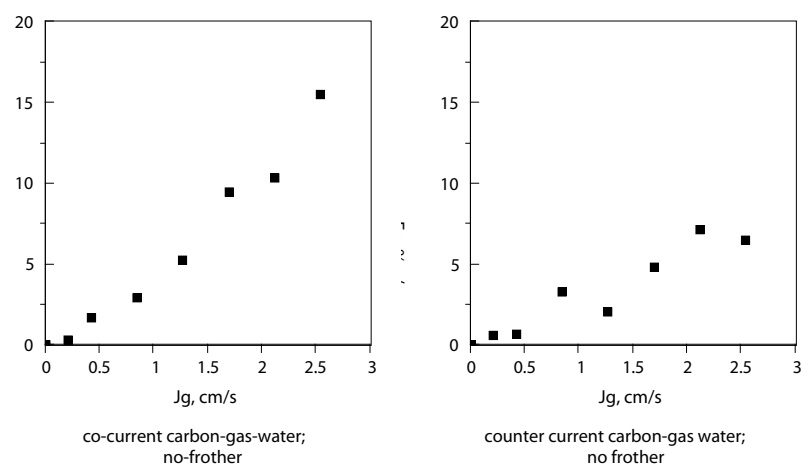

Fig. 4. Gas hold-up (Eg) comparison between co-current and counter-current flotation column operations for carbon-gas-water system without frother. 
the counter current column operation due to a larger relative phase velocity, since gas hold-up values are smaller than those presented in the co-current column operation under equivalent superficial gas velocities.

The slurry flotation systems were analysed with and without surfactant additions varying the superficial gas velocity. The experimental data confirm that slurries consisted in mixtures of water and hydrophobic solids (carbon) resulting in lower gas hold-up values, contrary to the gas hold-up values in slurries made of water and hydrophilic solids (silica).

Figure 5 presents the experimental points for gas hold-up measurements in the flotation systems, carbon $(5 \% \mathrm{w} / \mathrm{w})$ water slurries and silica $(5 \% \mathrm{w} / \mathrm{w})$ water slurries, as the superficial gas velocity varies in the column. The effect of surfactant additions is demonstrated through this plot.

The surfactant additions have confirmed that hydrophobic solids promote bubble coalescence by comparison with bubbling systems containing hydrophilic solid. The flotation system containing carbon slurry did not change appreciably the gas hold-up value under the presence of surfactant in the experimental range of superficial gas velocities.

On the other hand, the increase in gas hold-up with increasing surfactant concentration and the superficial gas velocity is very noticeable in the silica system. These observations suggest that the presence of hydrophilic solids promote the stability of the bubble-slurry dispersion, and hence decreasing bubble coalescence.

Bubble size is estimated from drift flux analysis as it is described in the literature $[12,13]$. Drift flux analysis was validated in two-phase systems [14, 15], and in three-phase systems [16], against an independent photographic method. Image-analysis results and the predictions from drift flux analysis were in good agreement; therefore, these experiences confirm the technique to be an accurate method to predict bubble size as first approximation.

The estimated Sauter bubble diameters [14] are presented in Figure 6 in terms of the gas hold-up values in the carbonwater and silica-water slurry systems. The surfactant additions effect can be seen in these bubbling systems.

Figure 7 shows that the gas hold-up increases as the bubble
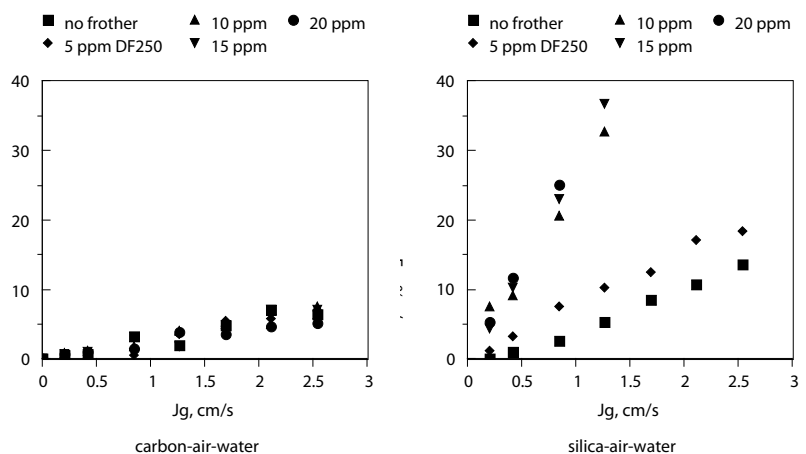

Fig. 5. Experimental gas hold-up (Eg) measurements in the carbonwater slurry and the silica-water slurry systems as a function of the superficial gas velocity $(\mathrm{Jg})$.
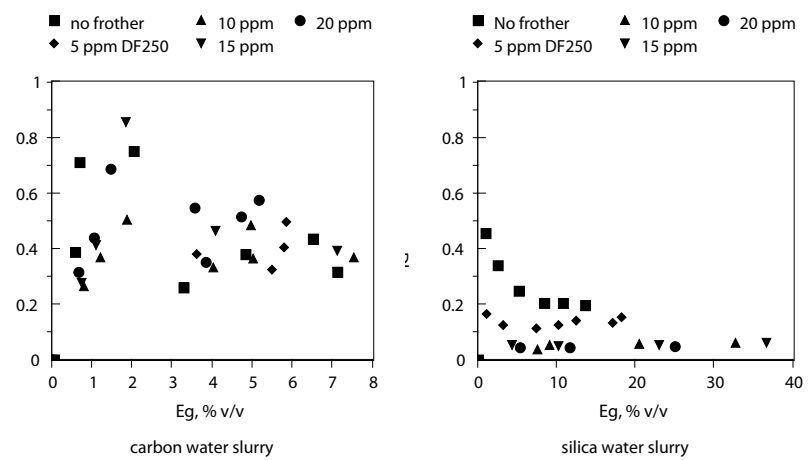

Fig. 6. Sauter mean bubble diameter $(\mathrm{Db})$ as a function of the gas hold-up (Eg) for the gas-slurry systems tested in this work.
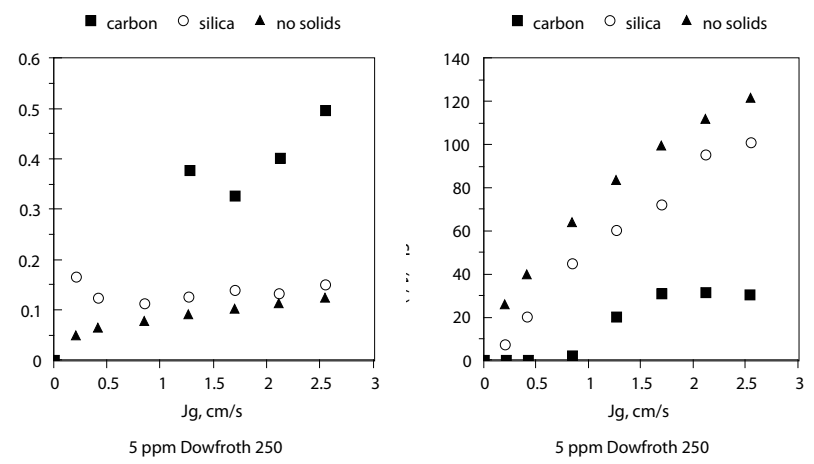

Fig. 7. Bubble diameter (Db), and superficial bubble surface flux $(\mathrm{Sb})$ changes with the superficial air flowrate $(\mathrm{Jg})$, for a system with surfactant addition.

size decreases; nevertheless, the presence of hydrophobic solids (carbon particles) promotes markedly the increase in bubble size, maintaining the gas hold-up value below $9 \%(\mathrm{v} / \mathrm{v})$. These experimental observations can be explained in terms of bubbles coalescence caused by the penetration of the hydrophobic particles among neighbouring bubbles, as it has been experimentally observed [1]. It can be seen that there is a scatter in the experimental relation between bubble diameter and gas hold-up when the slurry is made with hydrophobic particles which indicates a strong mixing caused by the formation of large bubbles in the flotation column, even under high surfactant concentration (20 ppm Dowfroth 250).

In contrast, when the flotation system consisted of a slurry with hydrophilic solids, both the gas hold-up and the bubble size observe small changes in the entire range of surfactant concentration (0-20 ppm), which looks like the image of a sort of bubbly gas flow regime in the flotation column. Standing from this observations it may indicate that the adsorbed water molecules on the hydrophilic solids protect the structure of the original bubble swarm preventing the bubbles from coalescence, even at very high gas hold-up values (above 30\% v/v), in the flotation system.

Once the bubble size is known, it is interesting to figure out the path of the superficial bubble surface flux, because this property of the flotation system describes the actual surface 
gas-vapour interface that is available to perform a collection process in a particular flotation system, and it holds the chemical, mechanical and geometry characteristics in a particular flotation system $[11,17]$. Figure 7 presents the change of the experimental bubble size estimates as well as the behaviour of the superficial bubble surface flux, with the change in the superficial gas velocity, under the presence of surfactant.

From the last figure it can be seen that bubble size is undeniably affected by the presence of solids, being larger in the case of slurry with hydrophobic particles as compared with the dispersion containing hydrophilic solids or no solids whatsoever. Larger bubbles produce a smaller liquid-vapour interface surface, as compared with the creation of that with smaller bubbles.

According to the literature [1], highly hydrophobic particles (carbon slurries) promote bubble coalescence and then the bubble surface area $(\mathrm{Sb})$ decreases. From the experimental results of this work, the low percentage of solids in the slurry is the reason of the short decrease in the Sb since the bubble coalescence is not excessive.

The effect of the slurry density on the gas-silica-water dispersions properties is shown in Figure 8. As can be observed, both the gas hold-up and the estimated bubble diameter are plotted versus the superficial gas velocity in the column.

It is clear that the presence of hydrophilic solids in the flotation column affects the gas hold-up which increases with the density of the slurry and with the superficial gas velocity (the last effect is due to the rise in the amount of gas fed into the flotation system).

An interesting feature to be noticed is that the bubble size decreases with the addition of the hydrophilic solids as compared with the system without solids; however, the density of the slurry does not affect de bubble diameter and it is only a function of the superficial gas velocity; in other words, for a given superficial gas velocity, and surfactant concentration, the bubble size is likely to be constant regardless the amount of hydrophilic solids in the slurry.

Changes in the superficial bubble surface with the bubble size and the gas hold-up is presented in Figure 9, for experiences after adding $20 \mathrm{ppm}$ of surfactant. It can be noticed a good straight correlation among the superficial bubble surface
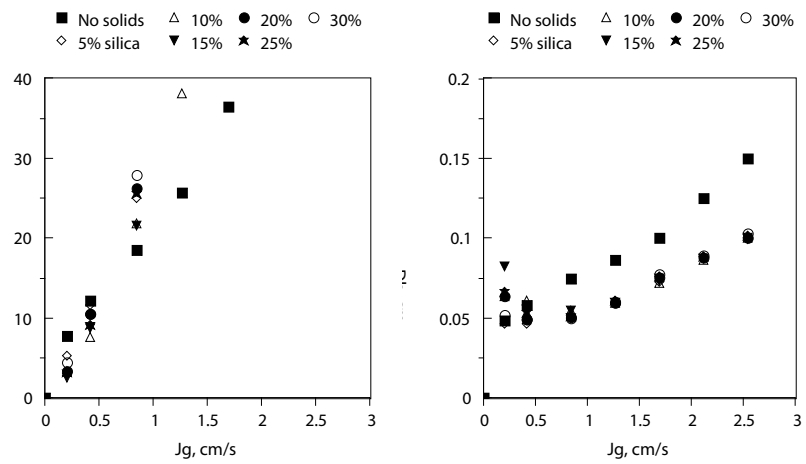

Fig. 8. Gas hold-up (Eg), and bubble size $(\mathrm{Db})$ behaviour in terms of the superficial gas velocity $(\mathrm{Jg})$, and the density of the slurry.
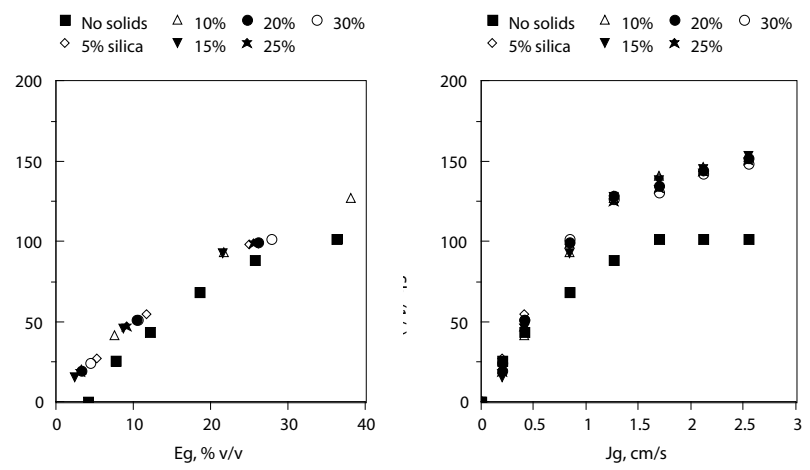

Fig. 9. The superficial bubble surface flux $(\mathrm{Sb})$ as a function of the gas hold-up (Eg), and the superficial gas velocity (Jg). Slurry with 20 ppm of surfactant.

flux and gas hold-up for gas hold-up values up to $25 \%$. This performance takes place in both flotation systems, with and without solids, being the superficial bubble surface flux slightly larger under the presence of solids. This behaviour can indicate that smaller bubble are produced when the slurry consists of hydrophilic solids in contrast with air-water dispersions.

Besides the bubble size, the experimental results indicate that there is an effect of the flotation system geometry on the behaviour of the superficial bubble surface flux.

When the bubbling system does not contain solids, there exists a limit for increasing the superficial bubble surface flux with the increase in the superficial gas velocity, this limit is at a superficial gas velocity of about $1 \mathrm{~cm} / \mathrm{s}$, above this limiting value the superficial bubble surface flux remains approximately constant (around $100 \mathrm{~s}^{-1}$ ). In the case of the flotation system with hydrophilic solids, the limiting value of the superficial gas velocity increases as well as the corresponding value of the superficial bubble surface flux. All this information suggests that depending on the bubble size, the space to retain a stable bubbles swarm depends from the flotation device geometry. This means that if the flotation system is pushed too much by increasing the gas flow rate, it can reach such limits producing an unstable flotation operation as a result of bubbles coalescence and an excessive circulation, mixing, and hence turbulence.

\section{Experimental}

The experiments in the present work were carried out in a 15cm-diameter (4-m-height) acrylic laboratory flotation column which was fully instrumented. Air was introduced through a porous metal sparger installed at the bottom of the column.

Series of stainless steel ring electrodes flushed to the internal surface of the wall column were installed in order to measure the electrical conductivity of the gas-liquid dispersion (experiments with no-solids), or the gas-slurry dispersion (hydrophilic solids or hydrophobic solids), by connecting properly arrays of electrodes creating conductivity flow cells [18]; also the conductivity of the liquid or slurry without bubbles was 


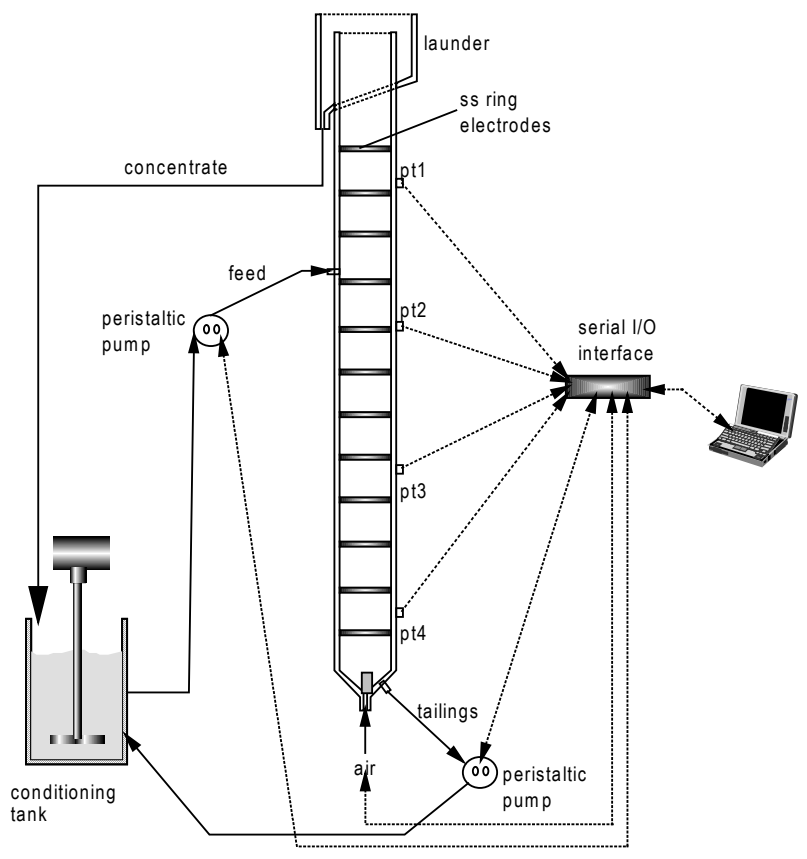

Fig. 10. Schematic representation of the experimental set up.

measured at the feed point in the column by means of a conductivity flow cell. With the liquid or slurry only conductivity and the gas-liquid or gas-slurry conductivity the gas hold-up (Eg) was estimated by applying Maxwell's model [19].

Additionally, four differential pressure transmitters were installed along the flotation column at different points separated a vertical distance to measure a difference in pressure between pairs of pressure taps to estimate gas hold-up [16].

The column was fed continuously with water (and frother additions: Dowfroth 250) or with solids-water slurries (hydrophobic solids: carbon-water; or, Hydrophilic solids: silicawater) by means of a variable speed peristaltic pump, and the flow of the tailings was controlled (as the superficial liquid or slurry velocity, Jl). The speed of the feed pump was used to control the froth depth at the top of the column. The current of concentrates and tailings were collected in the conditioning tank in order to be fed again to the flotation column.
Differential pressure and conductivity were simultaneously measured for all the air flowrates tested here, with the column run with water only or with slurry, both measurements were carried out in the same region of the column. The air flow rate was monitored and controlled using a mass flow controller. The experimental apparatus is shown in Figure 10.

\section{References}

1. Spyridopoulos, M.; Simons, S.; Neethilng, S.; Cillers, S. Physicochem. Probl. Miner. Process. 2004, 38, 37-52.

2. Barigou, M.; Greaves, M. Chem. Eng. Sci. 1992, 47, 2009-2025.

3. Cho, Y. S.; Laskowski, J. S. Int. J. Miner. Process. 2002, 64, 6980.

4. Grau, R. A.; Laskowski, J. S.; Heiskanen, K. Int. J. Miner. Process. 2005, 76, 225-233.

5. Camarasa, E.; Vial, C.; Poncin, S.; Wild, G.; Midoux, N.; Bouillard, J. Chem. Eng. Process. 1999, 38, 329-344.

6. Tse, K. L.; Martin, T.; McFarlane, C. M.; Nienow, A. W. Chem. Eng. Sci. 2003, 58, 275-286.

7. Escudero, R.; Tavera, F. J. Afinidad 2009, 544, 474-481.

8. Majumder, S. K.; Kundu, G.; Mukherjee, D. Chem. Eng. J. 2006, 122, 1-10.

9. Sweet, C.; van Hoogstraten, J.; Harris, M.; Laskowski, J. S. The Metallurgical Society of CIM, 1997, 235-245.

10. Cheng, Y. H.; Mikhail, M. W.; Salama, A. I. A.; Al Taweel, A. M. The Metallurgical Society of CIM, 1996, 3-11.

11. Gorain, B. K.; Manlapig, E. V.; Franzidis, J.-P. The Metallurgical Society of CIM, 1996, 299-313.

12. Finch, J. A.; Dobby, G. S. Column flotation. Pergamon, New York, 1990.

13. Banisi, S.; Finch, J. A. Miner. Eng. 1994, 7, 1555-1559.

14. Escudero-García, R. Characterization of rigid spargers and their selection for flotation columns. $\mathrm{PhD}$ thesis, McGill University, Canada, 1998.

15. Escudero-García, R.; Gomez, C. O.; Finch, J. A. The Metallurgical Society of CIM, 1998, May.

16. Uribe-Salas, A. Flotation of induced hydrophobic silica particles in a laboratory flotation column. Internal seminar, Instituto de Investigaciones Metalúrgicas, Morelia, Méx., 2001.

17. Gorain, B. K. The effect of bubble surface flux on the kinetics of flotation and its relevance to scale-up. $\mathrm{PhD}$ thesis, University of Queensland, Australia, 1997.

18. Tavera, F. J.; Gomez, C. O.; Finch, J. A. Can. Metall. Quart. 1998, $37,19-25$.

19. Maxwell, J. C. A treatise of electricity and magnetism. Oxford University Press, 1892, Vol 1 (II), 435-449. 